\section{Training}

Basic undergraduate training in the field of psychiatry forms part of the MD curriculum. This is in the form of formal lectures as well as clinical placement within the various mental health facilities (U niversity of Malta, 2003). 0 pportunities for postgraduate training in psychiatry include clinical placements at the levels of house officer (four posts) and senior house officer (seven posts), under the supervision of the consultant psychiatrists. Formal training in psychiatry leading on to full qualification as a psychiatrist is not provided in Malta and hence doctors must acquire formal training abroad.

The $N$ ational Agency against D rug and Alcohol Abuse provides basic training in substance misuse for those involved in service provision. It also offers a 'Voluntary Action Training Programme' for leading figures in the community, to facilitate a preventive approach with youths (Bugeja, 2000).

Membership of the Association of Maltese Specialists in Psychiatry provides the specialist registration of psychiatrists. Following recent developments, all psychiatrists will have recognition and registration of their specialty only if they are approved by the Association. There is no specialist registration for the other disciplines.

\section{Research activities}

M ental health research activities are conducted by each consultant on some practical aspect of psychiatric care. The aim of such research is the improvement of psychiatric care and its delivery. Research projects are usually conducted over a 12-month period and are funded in part by the Merit Award Scheme. 0 ther research activities are conducted by undergraduate and postgraduate students at the U niversity of Malta.

\section{Conclusion}

Mental health services in Malta are tailored to the sociocultural needs of the population. Provision of care tends to be personalised and holistic, with specialist care being an integral part of general psychiatric care. The national health service and services provided by both non-governmental organisations and the private sector function together, which allows individuals to choose their preferred option of care, and it is easy to switch between each mode of provision. The number of beds available for acute admissions is insufficient for the population, despite the relatively high number of psychiatric beds per 100000 population. This is likely to be a consequence of the custodial care approach employed and of ineffective community care. Although services have actively been trying to move away from institutionalisation to a more community-based setting, the limited number of fully qualified mental health professionals makes this move difficult. Investment in and upgrading of training and research among all disciplines would provide the basis for a more modern, community-based, multi-disciplinary approach to the delivery of mental health care.

\section{References}

Bell, A. (ed.) (1997) Sedqa Annual Report. Malta: Union Print Company.

Bugeja, S. (2000) A profile of Sedqa - the National Agency Against Drug and Alcohol Abuse, Malta. Substance $M$ isuse Bulletin, 13, 6 .

Ministry of Health (2004a) The Health of the Maltese Nation. Available at www.gov.mt. Last accessed 27 April 2004.

Ministry of Health (2004b) The Health Care System in Malta. Available at www.gov.mt. Last accessed 27 April 2004.

Ministry of Health (2004c) The Ministry. Available at www.gov.mt. Last accessed 27 April 2004.

N ational Statistics O ffice (2003) Demographic Review 2002. Valletta: N ational Statistics 0 ffice.

Sedqa (1994) Sedqa Mission Statement. Available at www.sedqa.org.mt. Last accessed 27 April 2004.

University of Malta (2003) Psychiatry Lecture Programme, MD Course Vth Year, Faculty of Medicine and Surgery. Available at http://home.um.edu.mt/med-surg/courses/vthyear/ psychiatryl.html. Last accessed 27 April 2004.

World Health Organization (2002) Atlas: Country Profiles on Mental Health Resources. Project Atlas: Country Profile: Malta. Geneva: WHO.

World Health Organization (2003) Atlas of Health in Europe. Geneva: WHO.
Although services have actively been

trying to move away from

institutionalisation

to a more

community-based setting, the limited

number of fully

qualified mental

health

professionals

makes this move difficult.

\section{Formal training in psychiatry leading on to full}

qualification as a psychiatrist is not provided in Malta and hence doctors must acquire

formal training abroad.

\title{
The mental health policies of Trinidad and Tobago
}

\author{
Hari D. Maharajhํㅡ and Akleema Ali²
}

${ }^{1}$ Senior Lecturer, Faculty of Medical Sciences, Department of Psychiatry, University of the West Indies, Mt Hope, Trinidad, West Indies, email drharim@carib-link.net

${ }^{2}$ PhD Student, Faculty of Social Sciences, Department of Behavioural Sciences, University of the West Indies, St Augustine, Trinidad, West Indies

he Republic of Trinidad and Tobago is the most southerly of the Caribbean island states. Trinidad is just $14 \mathrm{~km}$ from the coast of Venezuela. Trinidad covers an area of $4828 \mathrm{~km}^{2}$ while Tobago, the sister isle, has an area of 300 $\mathrm{km}^{2}$. The total population is approximately 1.3 million; $40.3 \%$ of the population is of East Indian descent, $39.6 \%$ of African descent, $18.4 \%$ mixed 
and $1.7 \%$ belong to other ethnic groups (Central Statistical O ffice, 2001). St Ann's Hospital in Port of Spain, the capital, was established in 1900 and is the country's only psychiatric hospital. There are two general hospitals, one in the north, at Port of Spain, and the other in the south, at San Fernando.

The per capita gross domestic product (GDP) is US\$8948 and total health expenditure represents $5.2 \%$ of GDP. Life expectancy at birth is 67.3 years for males and 72.6 years for females; a healthy life expectancy at birth is projected at 58.9 years for males and 62.0 years for females. Adult mortality is 235 per 1000 population for males and 150 per 1000 population for females; the male child mortality rate per 1000 population is 24 and the female rate is 18 per 1000 population (World $\mathrm{H}$ ealth 0 rganization, 2004). The literacy rate for males is $95.3 \%$ and that for females is $91.5 \%$ (World Health 0 rganization, 2002).

\section{Early mental health policies (1848-1975)}

Under British rule, the early treatment policies of the mentally ill in Trinidad paralleled the treatment of the insane in Britain. In 1848, an ordinance was passed to detain the criminally insane at the Royal $\mathrm{Gaol}$. The Belmont Lunatic Asylum was established in 1858. The facility later transferred to the St Ann's Asylum, now renamed the St Ann's H ospital. For the following five decades, policies of treatment were custo dial, with the use of malaria therapy for syphilis, insulin coma therapy, bromide mixtures, veronal and sulphonal, transorbital leucotomy, electroconvulsive therapy and immersion therapy in cold water.

The advent of chlorpromazine and the open-door policy of the 1950s heralded a period of aggressive treatment outside the hospital, with an emphasis on decentralisation and deinstitutionalisation as models of care. In that decade, two plans were also submitted: the Julien report of 1957 and the Lew is plan of 1959. In the latter, commissioned by the Ministry of $\mathrm{H}$ ealth, a recommendation was adopted for the creation of psychiatric units at the two general hospitals. In 1962, the Chan report recommended the subdivision of StAnn's Hospital into four autonomous units. However, this proposition received little attention.

\section{The Sectorisation Plan (1975)}

The Sectorisation Plan, adopted from the French model, was introduced in Trinidad and Tobago in 1975. The goals of this programme related to both community and institutional care. Its objectives were:

o to provide psychiatric care as near as possible to the patient's own home

O to upgrade the facilities of St Ann's H ospital, to reduce its size and to rehabilitate and return to the community the majority of its patients

o to introduce additional sub-specialist services (e.g. child guidance and geriatric services)

o to develop a system of consultation with the community, to ascertain their needs and their views

o to consult with community leaders of all sorts in the development of health attitudes and education programmes, aimed at prevention

o to integrate mental health care with general and public health care as far as possible

o to devise an effective system to evaluate this programme

0 to provide in-patient psychiatric services for patients (a proportion of beds in each sector would be general hospital beds)

o to set up out-patient services - wherever possible at district health offices

O to establish day and night hospitals

o to develop geriatric services

o to establish rehabilitation services - halfway houses, sheltered workshops, industrial therapy units

o to organise preventive services (e.g. early identification and work with special risk groups).

The plan divided the country into five sectors, each serving a population of approximately 200000 . Multidisciplinary teams were assigned to each sector and the regional hospitals were used for admissions. It was reported that a wave of excitement and enthusiasm engulfed all those involved, as it was felt to be the dawn of a new era in psychiatry in Trinidad and Tobago (James, 1984).

In June 1975, St Ann's Hospital was divided into four autonomous units and, together with the psychiatric unit at Port of Spain General H ospital, admitted patients from the five well-defined geographical areas (sectors). Patients from the city of Port of Spain and from Tobago were admitted to the General Hospital unit. The psychiatric unit at the San Fernando General Hospital formed an extension of one of the St Ann's $\mathrm{H}$ ospital units. $\mathrm{O}$ ut-patient clinics were set up in each sector. This was supported by Mental Health Act $\mathrm{N} 0$. 30 of 1975, which empowered mental health officers to treat patients. There are at present 75 out-patient clinics held monthly.

Towards the end of 1976, the initial enthusiasm of the Sectorisation Plan waned, as it became evident that the major objective of the programme, which was the decongestion of St Ann's H ospital and the treatment of patients in the community, was not being achieved. Adequate clinic facilities were lacking and no provision was made for hostels, halfway houses or sheltered workshops (James, 1984). Since 1975, there have been no major changes in community mental health in the Republic.

\section{The regional health authorities}

The Regional Health Authorities (RHA) Act N 0. 5 of 1994 led to the establishment of five health regions. This new policy proposed the realignment of the sectors to the RHA boundaries and a shift to wards primary care. The RHA Act legislated for the decentralisation of all health services and the five regions were empowered to develop their own psychiatric services. This generated some concern, since the only mental hospital in the 
country was situated in the $\mathrm{N}$ orth West Region and there was some ambiguity surrounding the allocation of human resources and infrastructure.

In 2000, the RHA Act was amended. The five regions were reduced to four, the Central Region being incorporated into the $\mathrm{N}$ orth West Regional Health Authority (N W RHA). The system is still in transition, as there are now two parallel administrative bodies, the Ministry of Health and the RHAs. In 2000, the psychiatric unit at the Port of Spain General H ospital was closed by the N W RHA and in 2003 the Ministry of H ealth aligned part of the Central Region to the South West Region.

\section{A new mental health plan (2000)}

Against the background of persisting problems with the mental health programme, the Trinidad and Tobago $\mathrm{N}$ ational M ental $\mathrm{H}$ ealth Policy and Plan was formulated by the Ministry of $\mathrm{H}$ ealth and the Pan American $\mathrm{H}$ ealth O rganization (PAHO) in 1995 and approved by Cabinet in 2000. The two main goals of this programme were to encourage the development of the highest level of mental health and to promote an adequate level of individualised care for those who have a mental disorder (M inistry of Health, 2000). The objectives of this new plan closely follow ed those of the Sectorisation Plan of 1975 and are as follows:

0 to educate the population regarding mental health and to promote healthy lifestyles

$o$ to reverse negative perceptions about mental disorders

$O$ to reduce the incidence of certain kinds of illnesses and disabilities

o to reduce mortality associated with certain kinds of mental disorder

o to provide adequate primary, secondary and tertiary care for persons with mental health problems, although with an emphasis on primary care

0 to integrate mental health with general health services as far as possible

o to develop linkages with other governmental, nongovernmental and consumer organisations

0 to undertake evaluation, research and training for improvement of the mental health services.

The delivery of the mental health services will now be the responsibility of the RHAs, while the Ministry of $\mathrm{H}$ ealth will be involved in the formulation and evaluation of policies. The RHAs have also established a $\mathrm{N}$ ational Mental Health Commission (N MHC) and a Regional Mental $\mathrm{H}$ ealth Committee (RMHC) in every sector for the implementation of the $\mathrm{N}$ ational Mental H ealth Policy and Plan. These coordinating committees are expected to formulate and implement specific plans of action in mental health. The most important function of the $\mathrm{N} \mathrm{MHC}$ includes the evaluation of the effectiveness and quality of services.

The following changes in the present system are proposed:

O St Ann's H ospital is to see a phased reduction in bed numbers, from 1026 to 600 o the Eric W illiams Medical Complex will provide inpatient child psychiatry care

O four extended care centres will provide 30 beds 10 for psychogeriatrics and 20 for rehabilitation

- San Fernando G eneral H ospital will provide 30 beds for acute psychiatric care

o residential units of 125 beds will provide care for patients with low levels of dependency

o non-residential day care units and sheltered workshops will be established

o a 25-bed psychiatric unit will be reopened at the Port of Spain G eneral H ospital.

Human resources are said to be the single most important component of the $\mathrm{N}$ ational Mental $\mathrm{H}$ ealth Policy and Plan. Multi-professional teams will provide services at primary, secondary and tertiary levels. The Plan proposes to have, in each region, at least one health facility that provides child guidance services, psychology services and occupational therapy. In addition, drug dependency services are provided at C aura and St Ann's Hospital.

\section{Training}

In 1987 a 4-year programme of the DM Psychiatry was introduced at the U niversity of the West Indies. To date, approximately 20 psychiatrists have graduated. Continuing medical education (CME) is ongoing and there is a proposal to make itmandatory.

\section{Personnel}

In 2001, there were 187 nursing aides and 1383 nursing assistants (C entral Statistical 0 ffice, 2001). There are at present 7.92 psychiatric beds per 10000 population in the only mental hospital and 0.24 psychiatric beds per 10000 population in general hospitals. There are 22 trained psychiatrists, 6 psychiatrists in training and 23 psychiatric social workers.

\section{Conclusion}

Psychiatry in Trinidad and Tobago remains a unique blend of current scientific knowledge purporting a neurobiological basis of diseases and traditional practices based on superstition, religion and folk medicine (Maharajh \& Parasram, 1999). O ver the years, changes have been minimal. Mental health planning for culturally diverse and secular communities are difficult to construct and even more difficult to implement. Policies must be tailored to suit the needs of the population, with solutions for people with mental disorders in developing countries (Jacob, 2001). The planning and delivery of services must have a clear focus and vision, supported by both efficient legal machinery and a willingness on the part of government to invest in a rolling programme of service improvement. Patients' rights and regard for the individual's autonomy are imperative. This is indeed a tall order for a developing country.
Towards the end of 1976, the initial enthusiasm of the Sectorisation Plan waned, as it became evident that the major objective of the programme,

which was the decongestion of St Ann's Hospital and

the treatment of patients in the community, was not being achieved.

\section{Psychiatry in \\ Trinidad and}

Tobago remains a unique blend of current scientific knowledge purporting a neurobiological basis of diseases and traditional practices based on superstition, religion and folk medicine. 
Maharajh, H. D. \& Parasram, R. (1999) The practice of psychiatry in Trinidad and Tobago. International Review of Psychiatry, 11, 173-183.

Central Statistical Office (2001) Statistics at a Glance. Port of Spain: Central Statistical O fice.

Jacob, K. S. (2001) Community care for people with mental disorders in developing countries. Problems and possible solutions. British Journal of Psychiatry, 178, 296-298.

James, V. (1984) A Review of Psychiatry in Trinidad and Tobago Over the Decade 1970-1980. Port of Spain: St Ann's Hospital.
Ministry of Health (2000) Mental Health Plan. Port of Spain Ministry of Health.

World Health O rganization (2002) Project Atlas: Country Profile Trinidad and Tobago. Geneva: WHO. Available at www.cvdinfobase.ca/mh-atlas/. Last accessed 29 April 2004.

World Health Organization (2004) Countries - Trinidad and Tobago. Geneva: WHO. See www.who.int/country/tto/en/. Last accessed 29 April 2004.

\title{
Postgraduate psychiatry training for global mental health: a Canadian experience
}

\author{
Sonia Chehil ${ }^{1}$ and Stan Kutcher $^{2}$
}

${ }^{1}$ Fellow in International Psychiatry, Department of Psychiatry, Dalhousie University, Canada, email Sonia.Chehil@Dal.Ca

${ }^{2}$ Associate Dean of International Medicine Development and Research, Dalhousie University; Professor and Head of the Division of International Psychiatry, Department of Psychiatry, Dalhousie University, Canada

s globalisation has diminished the distance between the developed and developing worlds, it has highlighted the impact of global health issues on domestic health concerns and has underscored the reality of global health disparities. In the Canadian context, there is a need for Canadian physicians to have an understanding of medicine from a global perspective and to appreciate and understand the impact of global health issues on both international and domestic health care. Consequently, there is a need to create and incorporate a global or international health curriculum into general as well as specialty physician training programmes. This will provide future physicians with the skills, knowledge and understanding necessary to provide globally informed practice in domestic as well as international health.

\section{The global mental health burden}

Training in and understanding of health issues from a global perspective is particularly relevant in the area of mental health. As the global burden of communicable diseases has decreased, mental illness has become one of the most common types of disabling disease worldwide (World Health O rganization, 2001). Mental disorders are now estimated to account for $12.3 \%$ of the global burden of disease and this is predicted to reach $15 \%$ by 2020 (Desjarlais et al, 1995; World Health O rganization, 2001).

Advances in the understanding of biological, social and epidemiological determinants of mental disorders, the development of effective treatments and service delivery models, and the implementation of mental health legislation and policy protecting the rights of people with a mental illness in the developed world have not to date been translated into applications which can be used by the majority of the world's population. In low- and middle-income countries (LMIC) there continues to be a dearth of effective mental health services, insufficient dedicated resources and an absence of effective mental health legislation for, as well as stigmatisation, discrimination and human rights abuses of, people with mental illness (D esjarlais et al, 1995).

$O$ ver the past decade, international agencies, including the World $\mathrm{H}$ ealth $O$ rganization and the World Bank, have increasingly recognised the need to make global mental health an international priority. The focus of the 2001 World H ealth Day celebration and the 2001 World Health Report on global mental health is an example of the commitment to highlight the global significance of mental disorders and to promote mental health reform worldwide (World Health O rganization, 2001).

\section{A Canadian initiative}

Canadian health training institutions have not kept pace with the increasing activities pertaining to global mental health. For example, in terms of physician training, there is currently no developed curriculum specifically focused on international mental health in C anadian postgraduate psychiatry training programmes. The grow th of cultural diversity within the $C$ anadian population has precipitated the development of a cultural psychiatry curriculum, which psychiatry residency training programmes across the 